\title{
O trabalho e a saúde do educador físico em academias: uma contradição no cerne da profissão
}

CDD. 20.ed. 306.361

796

http://dx.doi.org/10.1590/1807-55092014000400599
Alessandra Dias MENDES*

Paulo Henrique AZEVÊDO**
*Instituto de Educação, Ciência e Tecnologia de Brasília. ${ }^{* *}$ Faculdade de Educação Física, Universidade de Brasilia.

\section{Resumo}

0 esporte e a atividade física no Brasil estão expandindo em número de participantes e em diversificação de atividades. Nesta expansão se inclui o ramo de academias, no qual o Brasil está em quarto lugar no mercado mundial. Embora o Educador Físico (EF) pudesse ser beneficiado por esta expansão, isto não ocorre. E mesmo sendo destacado como agente promotor de saúde e qualidade de vida, são raras as pesquisas acerca de como a saúde e a qualidade de vida do EF são afetadas pela sua atuação profissional e condições de trabalho. 0 objetivo desta pesquisa foi trazer à evidência científica aspectos da atuação profissional e condições de trabalho do EF atuante em academias de Brasília (DF), sendo utilizada pesquisa descritiva com questionário semiaberto $(n=53)$. Verificou-se que o vertiginoso crescimento do ramo de academias, inclusive como lócus de trabalho preferencial dos recém-formados, não corresponde a melhores condições de trabalho para os EFs, haja vista a presença de informalidade, precarização, intensificação e flexibilização do trabalho, conduzindo o $\mathrm{EF}$ a trabalhar em diversos empregos [EFs possuem em média dois empregos $(54,7 \%)$, havendo EFs com quatro empregos $(9,4 \%)]$, gerando desgastes à sua saúde, caracterizando um contrassenso à essência da profissão. Denota-se condições de trabalho nem sempre favoráveis, mas mascaradas pela realização pessoal advinda da escolha vocacional da profissão. Foi verificada baixa conscientização, mobilização e criticidade dos EFs perante esta realidade, embora alguns tenham indicado o desejo de abandono da profissão. É necessário o estabelecimento de uma nova contratualidade.

Palavras-chave: Educação física; Atuação profissional; Condições de trabalho; Mercado de trabalho; Qualidade de vida no trabalho; Academia de ginástica.

\section{Introdução}

A expansão da área de Educação Física é materializada nas pesquisas de Alves ${ }^{1}$, Boschi², Capinus$s^{3} \mathrm{U}^{3}$ e DACosta ${ }^{4}$, cujos gráficos evidenciam dados surpreendentes sobre aspectos correspondentes a esse crescimento, como o aumento do número de praticantes de esportes e atividades físicas, do número de academias de atividades físicas e de cursos superiores em Educação Física no Brasil. Esse expressivo desenvolvimento reverbera nos locais de atuação profissional do Educador Físico ${ }^{\text {a, }}$, como evidencia Bertevello $^{6}$ ao destacar que 60 a $70 \%$ dos recémformados nos estados do Rio de Janeiro e São Paulo encontram seu primeiro emprego em academias.

A despeito de tais dados e das numerosas pesquisas e discursos que conclamam o alto valor da prática de atividade física em termos sociais e de saúde, há raros estudos na literatura científica ${ }^{\mathrm{b}}$ que abordam aspectos concernentes à atuação profissional, às condiçôes de trabalho, e suas respectivas repercussôes na saúde do "promotor" desta saúde através da atividade física, o Educador Físico (EF).

Este estudo vem, portanto, com demarcada originalidade, e relevância, ampliar e aprofundar as questôes acerca deste tema, infelizmente pouco presente na literatura. A originalidade deste estudo se deve pelo amplo leque de informaçóes possibilitado pelo desenho de pesquisac, bem como por ser o primeiro estudo na cidade de Brasília/DF, e o segundo no Brasil a investigar aspectos concernentes a atuação profissional e condiçôes de trabalho até a data de sua conclusão em $2010^{\mathrm{d}}$ - o primeiro estudo publicado foi o de Nogueira ${ }^{7}$ em 2006. 
A ocupação profissional, de modo geral, tem se instituído de uma contradição entre o sofrimento e o $\operatorname{prazer}^{7-8}$. É o que se observa ao analisar o quadro do mercado de trabalho na área de academias de atividades físicas, no atinente ao discurso dos Educadores Físicos (EFs), onde identificamos sua satisfação pessoal com o trabalho simultaneamente a queixas referentes às suas condiçóes de trabalho, e o recorrente uso da expressáo "correria" em referência ao volume de trabalho a que se submetem, trabalhando em vários locais, nem sempre com o devido contrato trabalhista legal, devido à desvalorização a que são submetidos.

Sua atuação profissional, pulverizada em diferentes empregos, parece deixá-los cansados e assoberbados de afazeres (ministrar e preparar aulas; deslocamentos em direção aos diferentes empregos; desgaste físico; etc.) gerando déficit de tempo para capacitar-se, para o lazer, autocuidado com a saúde, convívio em família, dedicação a projetos pessoais, entre outros, conduzindo-os assim a comprometer sua qualidade de vida bem como a qualidade de seu trabalho, o que por si só, produz uma contradição quanto à sua profissão, visto que degradam sua saúde em seu trabalho de zelar pela saúde de outros. Deduz-se desta

\section{Método}

Este estudo é classificado como uma pesquisa do tipo descritiva, cujo objetivo é a descrição das características de determinada população ou fenômeno, as quais são obtidas utilizando-se técnicas padronizadas de coleta de dados, tais como o questionário e a observação sistêmica ${ }^{11-14}$.

Para substanciar este trabalho, foi realizada pesquisa bibliográfica no Portal de Periódicos e no Banco de Teses da Coordenação de Aperfeiçoamento de Pessoal de Nível Superior, na Biblioteca Digital Brasileira de Teses e Dissertaçóes, no acervo da Biblioteca Central da Universidade de Brasília e nos sítios eletrônicos de revistas da área de Educação Física. Na pesquisa feita em diversas bases de dados, não foi delimitado período de publicação e foram utilizados os seguintes termos-chave: Educação Física; Professor de Educação Física; Profissional de Educação Física; Educador Físico; academia; atividade fisica; academias de atividades fisicas; mercado; trabalho; mercado de trabalho; relaçöes trabalhistas; contrato de trabalho; condiçóes de trabalho; atuaçẫo; atuação profissional.

A pesquisa realizada não forneceu muitos resultados, embora tenha sido criado um padrão de busca conjuntura que este mercado de trabalho para o EF, embora em crescimento, poderia ser considerado não promissor, o que leva muitas vezes ao abandono da profissão. Este desgaste, proveniente do excesso de horas e da intensificação do esforço físico e mental no trabalho, pode gerar a ocorrência de agravos à saúde.

Portanto, o presente estudo, buscou trazer à evidência científica, dados acerca das condiçóes de trabalho e de atuaçâo profissional dos EFs atuantes em academias de atividades físicas de Brasília (DF).

Esta pesquisa se institui importante principalmente em tempos em que se argumenta sobre o trabalho decente e a qualidade de vida no traba$l h o^{10}$. Tendo em vista a expansão deste setor e a reestruturação produtiva do mundo do trabalho, tal questionamento é primordial àqueles que têm a Educação Física como profissão. Ao contrário de todo o glamour que cerca a profissáo, que remete a ideias de juventude, diversão e vigor físico, há a realidade cotidiana de um trabalhador, passível de estudo e análise. Assim, esta pesquisa surge em meio a mudanças no mundo do trabalho como um questionamento acerca da valoração e do futuro da profissão do EF.

tido como abrangente. Observou-se que não há unicidade nos termos-chave utilizados nas pesquisas. Os resultados foram analisados, restando como pertinente a este estudo um total de 11 pesquisas publicadas. Das quais somente sete eram pertinentes ao escopo deste estudo, por abordarem aspectos concernentes a condiçôes de trabalho e atuação profissional do educador físico em academias de atividade física.

A partir do problema e do referencial encontrado, determinou-se o método utilizado neste estudo, o qual exigiu a construção de um questionário para coleta de dados de EFs atuantes em academias de atividades físicas da cidade de Brasília/DF. O questionário totalizou 59 questóes, as quais eram em sua quase totalidade objetivas. Algumas das informaçóes solicitadas no questionário foram: perfil do EF (sexo, idade, formação profissional e complementar, motivos de escolha da profissão, experiência profissional, quantidade de empregos, entre outros), aspectos concernentes a condiçóes de trabalho (tipo de contrato de trabalho, carga horária de trabalho, remuneração, entre outras) e atuação profissional (funçôes desempenhadas na academia, 
trabalho aos finais de semana, horário de descanso, entre outras), prática de atividade física, percepção de reconhecimento e valoração de sua profissão por outros, conhecimento da legislação trabalhista, filiação ao conselho profissional e ao sindicato, satisfação e pretensôes profissionais. Os questionários aplicados foram analisados no "software" Sphinx Plus², versão 5.1.0.2, sendo utilizada estatística descritiva com cálculos de média (M) e desvio-padrão (DP).

Do universo de 432 academias registradas no Conselho Regional de Educação Física (CREF - 7a Região), foram delimitadas quatro, por sua grande representatividade social em Brasília/DF e por serem representantes da época em que foram fundadas, distribuindo-se nas décadas de 70 a 2000 - classificadas como Média Empresa e Grande Empresa conforme BERTEVELLO $^{15}$. As academias foram contatadas com cartas de apresentação da universidade e do conselho profissional, o que facilitou a entrada em campo. Foram convidados a participar da pesquisa todos

\section{Resultados e discussão}

A pesquisa bibliográfica permitiu encontrar estudos sobre o EF em academias com foco em aspectos como formação, inserção no mercado de trabalho, atuação profissional, condiçóes de trabalho, e saúde. Os estudos encontrados e seus resultados sáo apresentados a seguir, e se tornaram referenciais para o delineamento da pesquisa executada neste estudo.

PALMA $^{16}$ tendo o EF como profissional de saúde e exemplo de "boa saúde" no imaginário social, promoveu uma investigação sobre os hábitos relacionados ao trabalho de EFs para verificar se sua condição condiz com tal imaginário. Dentre os dados, é digno de destaque: a) 29,73\% são sedentários; b) a média de horas de trabalho semanal foi de 48,6 h; c) o valor médio de esforço físico no trabalho pela Escala de Borg foi de 14,02 ; d) $51,35 \%$ reportaram dor relacionada à ocupação; e) 16,02\% apresentaram transtornos psíquicos; f) 16,22\% levavam até 1 h para almoçar; g) 18,92\% fizeram uso de aceleradores metabólicos e suplementos alimentares para diminuir a fadiga, dar aporte ao gasto calórico e fins estéticos.

Palma e Assis ${ }^{17}$ identificaram o quantitativo de EFs, atuantes em academias, usuários de esteróides anabólico-androgênicos (EAA) e aceleradores metabólicos (AM), bem como, as razôes que os conduzem a fazer uso de tais substâncias. Investigaram $305 \mathrm{EFs}$, e o levantamento permitiu observar que: os Educadores Físicos atuantes nas áreas de ginástica, musculação e natação em cada academia. A amostra foi composta de 52 Educadores Físicos, e não houve recusa na participação. A coleta de dados foi realizada entre 2 de dezembro de 2009 e 5 de janeiro de 2010.

Esta pesquisa foi submetida ao Comitê de Ética em Pesquisa com Seres Humanos Faculdade de Ciências da Saúde da Universidade de Brasília (CEP/FS/UnB), sendo aprovada sob o Registro No $128 / 2009$. Todos os participantes assinaram o Termo de Consentimento Livre e Esclarecido, ficando com cópia do mesmo, o qual continha os dados da autora da pesquisa e do CEP/FS/UnB.

No tópico Resultados e Discussão, apresentamos os principais resultados da revisão de literatura, seguido dos dados da pesquisa de campo, de modo a estabelecer um diálogo entre ambos, haja vista a pertinente relação, finalizando com uma análise específica do tema central, ou seja, a contradição encontrada no cerne da profissão.

a) 38,69\% já fez uso de AM na vida; b) 25,57\% de EAA; c) $17,38 \%$ das duas drogas; d) enquanto, $53,44 \%$ nunca fez uso dessas drogas na vida. Embora não se tenha uma base comparativa, pode-se perceber que os valores parecem elevados. Entre as justificativas havia: angariar um corpo necessário à atividade profissional, seja enquanto cartão de visita e comprovante de competência profissional, seja para aumentar o desempenho e reduzir o desgaste físico necessários à atuação em suas aulas.

PAlma et al. ${ }^{18}$ verificaram entre 448 estudantes de Educação Física, que: a) 19,2\% fazem ou já fizeram uso de EAA, e do total de estudantes que já trabalhavam na área; b) 39,4\% relataram dores associadas à ocupação profissional.

Palma et al. ${ }^{19}$, com o intuito de identificar a relação entre o processo de trabalho e a saúde de EFs que atuam em academia com atividades aquáticas, aplicaram questionário a 184 EFs. Destacaram que estes profissionais estão mais expostos às agressóes provenientes deste ambiente (rinites alérgicas, candidiase, câncer de pele, etc.). Dentre os que atuam em atividades aquáticas: a) 41,30\% trabalham acima de 45,1 horas por semana; e b) 52,7\% apresentaram queixa de dores, a qual foi explicada por fatores biomecânicos envolvidos nas tarefas profissionais - elevada permanência na posição de pé, postura inadequada, repetitividade da 
tarefa, constante utilização de esforço físico ${ }^{\text {h }}$. Contudo, os autores ressaltam que o $\mathrm{EF}$ frequentemente trabalha em mais de um local, por este motivo as características encontradas podem não refletir as condições de um só posto de trabalho ${ }^{19}$.

Espirito-Santo e MourấO ${ }^{20}$ identificaram que os EFs trabalharam em média 50,7 horas por semana. A maior parte do salário era vinculada ao serviço prestado de "personal trainer", relação de trabalho na qual o EF fica à margem dos benefícios sociais assegurados pela legislação trabalhista. "As mega-academias justificam o baixo valor de hora/aula com o argumento de que ao entrar na academia o profissional terá possibilidade de conseguir muitos alunos como personal trainer" ${ }^{\prime 20}$. Na realidade os EFs acabam se sujeitando a trabalhar um elevado número de horas para conseguir um salário digno, o que interfere em sua saúde e em seu estilo de vida. As autoras concluem que a saúde dos EFs está a serviço do trabalho, o que por si só é uma contradição para um profissional que atua na promoção da saúde de outros.

Nogueira ${ }^{7}$ objetivou, em sua tese, examinar a qualidade de vida no trabalho (QVT) de $103 \mathrm{EFs}$ atuantes em nove academias localizadas em diferentes bairros da cidade do Rio de Janeiro com alto Índice de Desenvolvimento Humano (IDH) classificadas como médias, grandes e mega empresas ${ }^{15}$, características semelhantes as estabelecidas como critérios para seleção das academias pesquisadas neste estudo. É importante ressaltar que Nogueira pesquisou academias dirigidas por profissionais de Educação Física, e o autor era, à época do estudo, gestor e docente no segmento de academias há mais de duas décadas ${ }^{7}$ (p.167). Como resultado geral $87,37 \%$ dos professores entrevistados classificaram suas academias como bons e até mesmo excelentes lugares para se trabalhar. É preciso olhar este resultado com moderação, pois esta visão de conjunto distorce e simula o contexto real. Analisando separadamente cada categoria identifica-se: 1) diferenças de sexismo; 2) ocorrência de modelos de gestáo por produção, os quais geram estresse e instabilidade entre os profissionais; 3) 60\% dos professores não possuíam outro vínculo empregatício, contudo, apenas 33\% tinham sua CTPS assinada sobre o total de vencimentos, $47,6 \%$ tinham a CTPS assinada sobre parte do valor total de vencimentos e $19,4 \%$ relataram trabalhar sem assinatura da CTPS; 4) foram encontradas diferentes formas de pagamento, por hora-aula, por número de aulas ministradas no mês, por número de alunos, ou pelo regime de quatro semanas e meiai; 5) ausência de pagamento sobre o repouso semanal; entre outros. $\mathrm{O}$ autor menciona que os EFs chegam à condição de quase diaristas da indústria inglesa os "journeymen" (p.189). Portanto, a despeito do resultado geral positivo, são retratados aspectos negativos em relação a: perspectiva sobre a carreira profissional ${ }^{7}$ (p.201); estabilidade no emprego ${ }^{7}$ (p.202); confiança nos dirigentes da academia ${ }^{7}$ (p.202); condiçôes de trabalho ${ }^{7}$ (p.205); estímulo e investimento para capacitação profissional ${ }^{7}$ (p.210); reconhecimento social por parte de alunos, dirigentes e colegas ${ }^{7}$ (p.212); intervalo entre as aulas ${ }^{7}$ (p.215); abertura para diálogo com os dirigentes da $\operatorname{academia}^{7}$ (p.216).

Milano et al. ${ }^{21}$ investigaram a relaçáo entre o trabalho e a saúde dos EFs que atuam com aulas de ciclismo "indoor" em academias do Rio de Janeiro. A média de horas semanais trabalhadas foi de $35,76 \mathrm{~h}$, sendo encontrados valores de até 83 horas semanais. A percepção do desgaste revelou queixa de dores (n = 35; 48,61\%) com um valor médio de 13,99 para escala de Borg. Verificou-se que uma grande parte dos trabalhadores tinha até $6 \mathrm{~h}$ de sono por noite. De Milano et al..$^{21}$, a restrição de horas de sono para uma duração média diária de 4,5 horas, acumulada ao longo da semana, pode provocar prejuízos ao desempenho, fadiga, confusão e aumento na probabilidade de ocorrência de acidentes de trabalho. Do total de EFs investigados, a grande maioria eram jovens ${ }^{21}$.

Benedetti e Ouriques ${ }^{22}$ pesquisaram EFs atuantes em aulas de ginástica em academia, os quais apresentam problemas relativos à saúde, como "perda de voz", distúrbios emocionais, entre outros. Através de uma entrevista informal, observação direta da situação de trabalho, e medidas dos níveis de pressáo sonora do ambiente, observaram que apenas $14 \%$ das academias trabalhava dentro dos limites de sons e ruídos estabelecidos pelas normas do Ministério do Trabalho. Os EFs ministram em média 42 aulas por semana, com escala de rodízio aos sábados. A academia adota o sistema BTS ${ }^{k}$, e os autores ressaltam que este tem a particularidade de ser desgastante, e afirmam que na Europa e na América do Norte são ministradas em média três aulas de BTS por dia. Constataram que os EFs sentem cansaço físico e mental, desgaste vocal, irritação e agressividade. Apesar disto, a maioria dos EFs foi enfática em dizer-se feliz profissionalmente, embora descontente com o salário. Os EFs relataram que a academia não fornece roupas, calçados e cursos de reciclagem. Os autores concluíram que a falta de adequação no ambiente de trabalho e a questão econômica podem dificultar o desempenho dos EFs.

Palma et al. ${ }^{23}$ investigaram um fato que circunda o EF no imaginário social, sua imagem como um 
indivíduo imune aos problemas de saúde, disposto a exercícios físicos, representando o ideal de corpo saudável. As academias de ginástica, espaços marcados pela mercantilização do corpo atlético são o palco principal dessa representação e, assim, a inserção e a manutenção do EF neste mercado de trabalho vêm atravessadas pela exigência desse padrão, o qual paradoxalmente repercute de forma prejudicial sobre a saúde desses profissionais. Dentre o total de EFs investigados a maioria era de jovens do sexo masculino e mais da metade destes possuía mais de um emprego, além de ter elevada quantidade de horas trabalhadas - em média $42 \mathrm{~h}$ semanais, sendo que $34,2 \%$ ultrapassaram 50 horas semanais, havendo valores de até $78 \mathrm{~h}$ semanais. Quanto a escolaridade, mais da metade dos EFs possui especializaçáo. $\mathrm{O}$ tempo destinado ao almoço foi considerado precário pelos autores, sendo de $31 \mathrm{~min}$ a $1 \mathrm{~h} 30 \mathrm{~min}$ para $82 \%$ dos entrevistados. O hábito de realizar exercícios físicos, contudo, não esteve ameaçado, havendo elevada taxa de adesáo. $\mathrm{O}$ valor médio para o esforço físico percebido no trabalho é "pouco intenso", o que pode representar uma intensidade entre 40 a $60 \%$ ou o limiar anaeróbio em indivíduos não treinados. Essas exigências provêm da necessidade de realizar as aulas junto aos alunos, transportar pesos (caneleiras, halteres, anilhas, barras, etc.) para os alunos ou mesmo para arrumar a sala, além da necessidade de realizar, nos alunos, exercícios de alongamentos, fontes mais referidas para as queixas de dor. Dentre as variáveis independentes que apresentaram forte associação com o adoecimento, figurando possíveis fatores de risco temos: o ciclismo indoor, associado ao relato de doenças em 37,5\% dos professores; a realização de horas extras, onde aqueles que fazem horas extras mostram-se mais propensos à ocorrência de doenças; e poucas horas de sono. Foi verificado que, ao menos uma vez, $32,2 \%$ dos professores usaram drogas com base em efedrina com o objetivo de suportar o esforço físico e para emagrecer, 20,1\% relataram uso de EAA para aumentar a massa muscular ${ }^{23}$.

KRUG et al. ${ }^{24}$ tencionaram conhecer o perfil do profissional de Educação Física que atua na área de musculação em 10 grandes academias da regiáo central da cidade de Criciúma/SC. Dentre os que reportaram insatisfação profissional, 55,5\% alegaram a baixa remuneração como motivo de desistência da profissão, e 33,3\% apontaram a desvalorização profissional como motivo de desistência.

Palma et al. ${ }^{25}$, investigaram a associação entre o nível de ruído no ambiente de trabalho do professor de educação fisisca durante as aulas de ciclismo "indoor".
Observou-se que o tempo médio de trabalho foi de 30,5 horas/semana, sendo o tempo médio de trabalho com ciclismo "indoor" de 10,7 horas/ semana e com atividades que requeriam a utilização de música foram 23,3 horas/semana. Quanto aos valores de pressão sonora, em qualquer situação os valores médios encontraram-se distribuídos em maior número em faixas consideradas insalubres. Houve poucas diferenças entre os níveis de ruído e o porte das academias. Os problemas relacionados à garganta $(53,3 \%)$ e à audição $(26,7 \%)$ ou no ouvido estiveram entre os mais reportados. Em relação à organização e ao processo de trabalho dos professores, apenas três $(20,0 \%)$ utilizavam o microfone para proteção das cordas vocais e nenhum deles utilizava protetores auriculares. Os profissionais relataram que nunca foram fornecidos aparelhos pela academia. As salas eram construídas de materiais náo adequados para absorção do som. Os profissionais trabalhavam, em suas aulas, com valores médios próximos de $90 \mathrm{~dB}(\mathrm{~A})$, considerando o fato de que o profissional pode atuar em mais de uma aula por dia, concluem que o EF está atuando em um ambiente insalubre, e apontam outras investigaçóes ${ }^{1}$ semelhantes $^{25}$. PALma et al. ${ }^{25}$ alertam que a pressão sonora tem sido associada ao risco de desenvolver hipertensão arterial $^{23}$, além de influenciar negativamente o sono, provocar alteraçóes gástricas e repercutir sobre a visão e a concentraçáo.

Após análise dos estudos encontrados, focamos este estudo nas categorias Trabalho e Saúde de modo a agrupar aspectos atinentes à práxis do Educador Físico na(s) academia(s) de atividades físicas, relacionados à sua atuação profissional e condiçōes de trabalho, e as reverberaçóes destes em sua saúde. Destarte, procedemos à coleta de dados junto aos EFs atuantes em academias de atividades física na cidade de Brasília/DF. A pesquisa empírica executada neste estudo, cujos resultados são apresentados a seguir, será simultaneamente dialogada com os dados encontrados na pesquisa bibliográfica.

O questionário elaborado exclusivamente para esta pesquisa buscava ${ }^{\mathrm{m}}$ abranger aspectos que descrevessem basicamente: 1) a carga total de trabalho do EF - quantos empregos possui, quantas horas trabalha por semana, que funçóes executa, quanto tempo leva para se deslocar entre os empregos; 2) e seu investimento em autocuidado com a saúde, prática de atividade física e qualidade de vida; 3 ) sua percepção quanto a valoraçãon ${ }^{\mathrm{n}}$ de sua profissão e suas pretensóes profissionais.

A amostra foi composta de 52 Educadores Físicos graduados no curso superior de Educação Física - a 
maioria em instituição privada - e um Educador Físico provisionado, com predominância do sexo masculino em todas as academias (ver TABELA 8), sendo 36 homens e 17 mulheres com idade média e desvio-padrão de 31 anos $\pm 7,48$ anos. A maior parte da amostra se concentrou na faixa etária de 26 a 30 anos.
É interessante observar, que, como esperado, a escolha da profissão se dá, em geral por gosto pessoal, escolha, realização pessoal (ver TABELA 1). O que possivelmente justifica a satisfação deste profissional a despeito de suas condiçóes de trabalho, não só em academias como também em escolas ${ }^{26}$.

TABELA 1 - Motivos que determinaram a escolha pela profissão, apresentados em ordem decrescente de marcação.

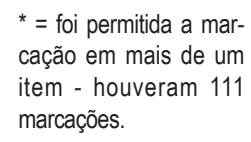

\begin{tabular}{|c|c|c|c|c|c|c|}
\hline \multirow{3}{*}{ Motivo de escolha da profissáa* } & & & \multicolumn{4}{|c|}{ Sexo } \\
\hline & \multicolumn{2}{|c|}{ Total } & \multicolumn{2}{|c|}{$\mathbf{M}$} & \multicolumn{2}{|c|}{$\mathbf{F}$} \\
\hline & $\mathbf{n}$ & $\%$ & $\mathbf{n}$ & $\%$ & $\mathbf{n}$ & $\%$ \\
\hline Realização pessoal & 29 & 26,1 & 19 & 17,1 & 10 & 9,0 \\
\hline Sabia exatamente que este era o curso que eu queria & 24 & 21,6 & 15 & 13,5 & 9 & 8,1 \\
\hline Outros & 2 & 1,8 & 1 & 0,9 & 1 & 0,9 \\
\hline Facilidade de acesso no vestibular & 1 & 0,9 & 0 & 0,0 & 1 & 0,9 \\
\hline Falta de opção & 0 & 0,0 & 0 & 0,0 & 0 & 0,0 \\
\hline Curso de fácil realização & 0 & 0,0 & 0 & 0,0 & 0 & 0,0 \\
\hline
\end{tabular}

Outro dado relevante de caracterização da amostra é que muitos começaram a atuar profissionalmente mesmo antes de concluir sua formação (TABELA 2). Quando se compara o ano de início da atuação ao ano de formação, parece haver uma entrada no mercado de trabalho anterior à formação, visto que foi pedido ao EF que considerasse sua entrada no mercado de trabalho na área, ainda que em forma de estágio. Tal fato é positivo quando se pensa na aquisição de experiência por parte do EF. Entretanto, muitas vezes, encontram-se EFs em formação atuando como profissionais e não como estagiários.

Em relação ao número de empregos por EF nossos dados corroboram o encontrado nas pesquisas de Delgado ${ }^{27}$ e Palma et al. ${ }^{25}$, ao evidenciar que a maioria dos EF possui mais de um emprego. Nos resultados desta pesquisa a maioria possui dois empregos $(81,1 \%)$, e alguns $(9,4 \%)$ chegam a ter até a ter quatro empregos (ver TABELA 3). Ao verificar os motivos referentes à quantidade de empregos foi possível observar, que as justificativas em sua maioria se resumem a fatores de renda (ver TABELA 4).

A média da carga horária na academia pesquisada (Emprego 1) foi de $20 \mathrm{~h}$ semanais, sendo a mínima de 5 h semanais e máxima de mais de 40 h semanais (ver TABELA 5). A carga horária, quando observada isoladamente por cada emprego, parece baixa, entretanto, quando se somam as cargas horárias de todos os empregos esses profissionais perfazem uma elevada carga horária.

Em relação aos deslocamentos entre os empregos, houve baixa taxa de resposta, com tempo variando entre 20 a 40 minutos. 
TABELA 2 - Ano em que começou a atuar na área de Educação Física e ano em que se formou (n = 52) ou ano em que obteve a chancela de provisionado $(n=1)$ pelo conselho profissional.

\begin{tabular}{|c|c|c|c|c|c|c|}
\hline \multirow{3}{*}{ Características } & & & \multicolumn{4}{|c|}{ Sexo } \\
\hline & \multicolumn{2}{|c|}{ Total } & \multicolumn{2}{|c|}{$\mathbf{M}$} & \multicolumn{2}{|c|}{$\mathbf{F}$} \\
\hline & n & $\%$ & $\mathbf{n}$ & $\%$ & $\mathbf{n}$ & $\%$ \\
\hline \multicolumn{7}{|c|}{ Ano em que começou a atuar na área } \\
\hline Sem resposta & 1 & 1,9 & 1 & 1,9 & 0 & 0,0 \\
\hline Entre 1965 e 1970 & 1 & 1,9 & 1 & 1,9 & 0 & 0,0 \\
\hline Entre 1971 e 1975 & 0 & 0,0 & 0 & 0,0 & 0 & 0,0 \\
\hline Entre 1976 e 1980 & 1 & 1,9 & 1 & 1,9 & 0 & 0,0 \\
\hline Entre 1981 e 1985 & 1 & 1,9 & 1 & 1,9 & 0 & 0,0 \\
\hline Entre 1986 e 1990 & 1 & 1,9 & 0 & 0,0 & 1 & 1,9 \\
\hline Entre 1991 e 1995 & 2 & 3,8 & 2 & 3,8 & 0 & 0,0 \\
\hline Entre 1996 e 2000 & 15 & 28,4 & 8 & 15,1 & 7 & 13,2 \\
\hline Entre 2001 e 2005 & 24 & 45,3 & 17 & 32,1 & 7 & 13,2 \\
\hline Entre 2006 e 2010 & 8 & 15,1 & 6 & 11,3 & 2 & 3,8 \\
\hline \multicolumn{7}{|c|}{ Ano em que se formou em Educaçáo Física } \\
\hline Sem resposta & 3 & 5,7 & 1 & 1,9 & 2 & 3,8 \\
\hline Entre 1965 e 1970 & 0 & 0,0 & 0 & 0,0 & 0 & 0,0 \\
\hline Entre 1971 e 1975 & 0 & 0,0 & 0 & 0,0 & 0 & 0,0 \\
\hline Entre 1976 e 1980 & 0 & 0,0 & 0 & 0,0 & 0 & 0,0 \\
\hline Entre 1981 e 1985 & 0 & 0,0 & 0 & 0,0 & 0 & 0,0 \\
\hline Entre 1986 e 1990 & 3 & 5,7 & 2 & 3,8 & 1 & 1,9 \\
\hline Entre 1991 e 1995 & 1 & 1,9 & 1 & 1,9 & 0 & 0,0 \\
\hline Entre 1996 e 2000 & 4 & 7,6 & 2 & 3,8 & 2 & 3,8 \\
\hline Entre 2001 e 2005 & 15 & 28,3 & 11 & 20,8 & 4 & 7,5 \\
\hline Entre 2006 e 2010 & 27 & 50,9 & 19 & 35,8 & 8 & 15,1 \\
\hline \multicolumn{7}{|c|}{ TABELA 3 - Quantidade de empregos do EF. } \\
\hline \multirow{3}{*}{$\begin{array}{l}\text { Quantidade de empregos do EF } \\
\text { atuante em academias }\end{array}$} & \multirow{2}{*}{\multicolumn{2}{|c|}{ Total }} & \multicolumn{4}{|c|}{ Sexo } \\
\hline & & & \multicolumn{2}{|c|}{$\mathbf{M}$} & \multicolumn{2}{|c|}{$\mathbf{F}$} \\
\hline & $\mathbf{n}$ & $\%$ & $\mathbf{n}$ & $\%$ & $\mathbf{n}$ & $\%$ \\
\hline Sem resposta & 1 & 1,9 & 1 & 1,9 & 0 & 0,0 \\
\hline 1 emprego & 9 & 17,0 & 5 & 9,4 & 4 & 7,5 \\
\hline 2 empregos & 29 & 54,7 & 22 & 41,5 & 7 & 13,2 \\
\hline 3 empregos & 9 & 17,0 & 4 & 7,5 & 5 & 9,4 \\
\hline 4 empregos & 5 & 9,4 & 4 & 7,5 & 1 & 1,9 \\
\hline
\end{tabular}

TABELA 4- Motivos apontados para explicar a quantidade de empregos do EF.

\begin{tabular}{|c|c|c|c|c|c|c|}
\hline \multirow{3}{*}{ Por que possui esta quantidade de empregos? } & & & \multicolumn{4}{|c|}{ Sexo } \\
\hline & \multicolumn{2}{|c|}{ Total } & \multicolumn{2}{|c|}{ M } & \multicolumn{2}{|c|}{$F$} \\
\hline & $\mathbf{n}$ & $\%$ & n & $\%$ & $\mathbf{n}$ & $\%$ \\
\hline Sem resposta & 11 & 20,8 & 7 & 13,2 & 4 & 7,5 \\
\hline Necessidade financeira & 5 & 9,4 & 2 & 3,8 & 3 & 5,7 \\
\hline Aumentar a renda & 7 & 13,2 & 5 & 9,4 & 2 & 3,8 \\
\hline $\begin{array}{l}\text { Para ter renda suficiente nesta área precisamos } \\
\text { trabalhar em mais de um emprego }\end{array}$ & 2 & 3,8 & 1 & 1,9 & 1 & 1,9 \\
\hline Para me manter financeiramente independente & 3 & 5,7 & 3 & 5,7 & 0 & 0,0 \\
\hline $\begin{array}{l}\text { Foi possível encaixar os horários, pois tenho } \\
\text { pouca carga horária em cada um deles }\end{array}$ & 1 & 1,9 & 1 & 1,9 & 0 & 0,0 \\
\hline Outro & 24 & 45,3 & 17 & 32,1 & 7 & 13,2 \\
\hline
\end{tabular}

Rev Bras Educ Fís Esporte, (São Paulo) 2014 Out-Dez; 28(4):599-615 • 605 
TABELA 5- Carga horária respectiva a quantidade de empregos do EF.

\begin{tabular}{|c|c|c|c|c|c|c|}
\hline \multirow{3}{*}{ Carga horária por emprego } & & & \multicolumn{4}{|c|}{ Sexo } \\
\hline & \multicolumn{2}{|c|}{ Total } & \multicolumn{2}{|c|}{ M } & \multicolumn{2}{|c|}{ F } \\
\hline & $\mathbf{n}$ & $\%$ & $\mathbf{n}$ & $\%$ & $\mathbf{n}$ & $\%$ \\
\hline \multicolumn{7}{|l|}{ Carga horária emprego 1} \\
\hline Sem resposta & 7 & 13,2 & 5 & 9,4 & 2 & 3,8 \\
\hline Menos de $5 \mathrm{~h}$ & 2 & 3,8 & 0 & 0,0 & 2 & 3,8 \\
\hline Entre $5 \mathrm{~h} \mathrm{e} 10 \mathrm{~h}$ & 12 & 22,6 & 7 & 13,2 & 5 & 9,4 \\
\hline Entre $10 \mathrm{~h}$ e $20 \mathrm{~h}$ & 21 & 39,6 & 16 & 30,2 & 5 & 9,4 \\
\hline Entre $20 \mathrm{~h}$ e $30 \mathrm{~h}$ & 10 & 18,9 & 7 & 13,2 & 3 & 5,7 \\
\hline Entre $30 \mathrm{~h} \mathrm{e} 40 \mathrm{~h}$ & 0 & 0,0 & 0 & 0,0 & 0 & 0,0 \\
\hline Mais de $40 \mathrm{~h}$ & 1 & 1,9 & 1 & 1,9 & 0 & 0,0 \\
\hline \multicolumn{7}{|l|}{ Carga horária emprego 2} \\
\hline Sem resposta & 16 & 30,2 & 9 & 17,0 & 7 & 13,2 \\
\hline Menos de $5 \mathrm{~h}$ & 4 & 7,5 & 3 & 5,7 & 1 & 1,9 \\
\hline Entre $5 \mathrm{~h} \mathrm{e} 10 \mathrm{~h}$ & 12 & 22,6 & 7 & 13,2 & 5 & 9,4 \\
\hline Entre $10 \mathrm{~h}$ e $20 \mathrm{~h}$ & 10 & 18,9 & 8 & 15,1 & 2 & 3,8 \\
\hline Entre $20 \mathrm{~h}$ e $30 \mathrm{~h}$ & 5 & 9,4 & 3 & 5,7 & 2 & 3,8 \\
\hline Entre $30 \mathrm{~h}$ e $40 \mathrm{~h}$ & 3 & 5,7 & 3 & 5,7 & 0 & 0,0 \\
\hline Mais de $40 \mathrm{~h}$ & 3 & 5,7 & 3 & 5,7 & 0 & 0,0 \\
\hline \multicolumn{7}{|l|}{ Carga horária emprego 3} \\
\hline Sem resposta & 42 & 79,2 & 30 & 56,6 & 12 & 22,6 \\
\hline Menos de $5 \mathrm{~h}$ & 2 & 3,8 & 1 & 1,9 & 1 & 1,9 \\
\hline Entre $5 \mathrm{~h} \mathrm{e} 10 \mathrm{~h}$ & 6 & 11,3 & 4 & 7,5 & 2 & 3,8 \\
\hline Entre $10 \mathrm{~h} \mathrm{e} 20 \mathrm{~h}$ & 2 & 3,8 & 1 & 1,9 & 1 & 1,9 \\
\hline Entre $20 \mathrm{~h}$ e $30 \mathrm{~h}$ & 1 & 1,9 & 0 & 0,0 & 1 & 1,9 \\
\hline Entre $30 \mathrm{~h}$ e $40 \mathrm{~h}$ & 0 & 0,0 & 0 & 0,0 & 0 & 0,0 \\
\hline Mais de $40 \mathrm{~h}$ & 0 & 0,0 & 0 & 0,0 & 0 & 0,0 \\
\hline \multicolumn{7}{|l|}{ Carga horária emprego 4} \\
\hline Sem resposta & 51 & 96,2 & 32 & 64,2 & 19 & 32,1 \\
\hline Menos de $5 \mathrm{~h}$ & 2 & 3,8 & 2 & 3,8 & 0 & 0,0 \\
\hline Entre $5 \mathrm{~h} \mathrm{e} 10 \mathrm{~h}$ & 0 & 0,0 & 0 & 0,0 & 0 & 0,0 \\
\hline Entre $10 \mathrm{~h} \mathrm{e} 20 \mathrm{~h}$ & 0 & 0,0 & 0 & 0,0 & 0 & 0,0 \\
\hline Entre $20 \mathrm{~h}$ e $30 \mathrm{~h}$ & 0 & 0,0 & 0 & 0,0 & 0 & 0,0 \\
\hline Entre $30 \mathrm{~h}$ e $40 \mathrm{~h}$ & 0 & 0,0 & 0 & 0,0 & 0 & 0,0 \\
\hline Mais de $40 \mathrm{~h}$ & 0 & 0,0 & 0 & 0,0 & 0 & 0,0 \\
\hline
\end{tabular}

Quando solicitado ao EF que apontasse quais funções exercia na academia, isto é, que atribuiçōes possuía, e, consequentemente, o que o empregador lhe requeria em relação à sua atuação profissional, notou-se pelas respostas que eles estáo sujeitos aos instrumentos de intensificação e flexibilização do trabalho estudados por DaL Rosso ${ }^{28}$, quais sejam "Polivalência, Versatilidade e Flexibilidade", "Ritmo e Velocidade", "Acúmulo de atividades", e "Gestão por resultados". Embora tenha ocorrido um número pequeno de marcações, nota-se pela não abstenção dos itens, que os EFs se identificam com múltiplas funçôes na academia (ver TABELA 6). Ainda, ao serem indagados se eram remunerados por comparecerem a reunióes de trabalho, $92,5 \%$ reportaram que não (ver TABELA 7). 
TABELA 6 - Funções exercidas pelo EF na academia.

\begin{tabular}{|c|c|c|c|c|c|c|}
\hline \multirow{3}{*}{ Funçóes exercidas na academia } & & & \multicolumn{4}{|c|}{ Sexo } \\
\hline & \multicolumn{2}{|c|}{ Total } & \multicolumn{2}{|c|}{$\mathbf{M}$} & \multicolumn{2}{|c|}{$\mathbf{F}$} \\
\hline & $\mathbf{n}$ & $\%$ & $\mathbf{n}$ & $\%$ & n & $\%$ \\
\hline Sem resposta & 1 & 0,3 & 0 & 0,0 & 1 & 0,3 \\
\hline Recepcionista & 33 & 8,8 & 20 & 5,3 & 13 & 3,5 \\
\hline Avaliador físico & 20 & 5,3 & 15 & 4,0 & 5 & 1,3 \\
\hline Árbitro & 13 & 3,5 & 9 & 2,4 & 4 & 1,1 \\
\hline Educador & 29 & 7,8 & 19 & 5,1 & 10 & 2,7 \\
\hline Pesquisador & 33 & 8,8 & 20 & 5,3 & 13 & 3,5 \\
\hline Técnico & 19 & 5,1 & 14 & 3,7 & 5 & 1,3 \\
\hline Preparador físico & 34 & 9,1 & 27 & 7,2 & 7 & 1,9 \\
\hline Recreador & 31 & 8,3 & 21 & 5,6 & 10 & 2,7 \\
\hline Atleta & 24 & 6,4 & 12 & 3,2 & 12 & 3,2 \\
\hline "Terapeuta" & 44 & 11,8 & 29 & 7,8 & 15 & 4,0 \\
\hline "Personal trainer" & 46 & 12,3 & 32 & 8,6 & 14 & 3,7 \\
\hline Coordenador de área ou geral & 18 & 4,8 & 14 & 3,7 & 4 & 1,1 \\
\hline Psicomotricista & 27 & 7,2 & 20 & 5,3 & 7 & 1,9 \\
\hline Todas estas & 2 & 0,5 & 2 & 0,5 & 0 & 0,0 \\
\hline
\end{tabular}

* $=$ foi permitida a marcação em mais de um item - houve 374 marcações.

TABELA 7 - Hora-extra, trabalho nos fins de semana, folga semanal, e remuneração em reuniões de trabalho do EF.

\begin{tabular}{|c|c|c|c|c|c|c|}
\hline \multirow{3}{*}{ Aspectos } & & & \multicolumn{4}{|c|}{ Sexo } \\
\hline & \multicolumn{2}{|c|}{ Total } & \multicolumn{2}{|c|}{ M } & \multicolumn{2}{|c|}{$\mathbf{F}$} \\
\hline & $\mathbf{n}$ & $\%$ & n & $\%$ & n & $\%$ \\
\hline \multicolumn{7}{|c|}{ Permanece na empresa após o horário de trabalho (por motivo de trabalho)? } \\
\hline Sim & 7 & 13,2 & 4 & 7,5 & 3 & 13,2 \\
\hline Não & 46 & 86,8 & 32 & 60,4 & 14 & 86,8 \\
\hline \multicolumn{7}{|c|}{ Trabalha nos fins de semana? } \\
\hline Sim & 39 & 73,6 & 26 & 49,1 & 13 & 24,5 \\
\hline Não & 14 & 26,4 & 10 & 18,9 & 4 & 7,5 \\
\hline \multicolumn{7}{|c|}{ Tem dia de folga durante a semana? } \\
\hline Sim & 24 & 45,3 & 15 & 28,3 & 9 & 17,0 \\
\hline Não & 29 & 54,7 & 21 & 39,6 & 8 & 15,1 \\
\hline \multicolumn{7}{|c|}{ É remunerado para estar presente em reunióes de trabalho? } \\
\hline Sim & 1 & 1,9 & 1 & 1,9 & 0 & 0,0 \\
\hline Algumas vezes & 3 & 5,7 & 3 & 5,7 & 0 & 0,0 \\
\hline Não & 49 & 92,5 & 32 & 60,4 & 17 & 32,1 \\
\hline
\end{tabular}

Analisando por academia, pode-se notar que não há uma uniformidade contratual (ver TABELA $8 \mathrm{e}$ 9). Uma explicação possível é o fato de que algumas modalidades, principalmente as da categoria ginástica, além de serem ofertadas esporadicamente na academia, exigem um profissional que domine sua técnica específica, com isto, as academias realizam um contrato de tempo parcial, cuja carga horária é inferior à 25 h semanais. Surpreendentemente, observa-se a predominância de Carteira de Trabalho e Previdência Social (CTPS) assinada sobre o valor total pago, sendo o maior valor percentual o encontrado na academia representante da/e fundada na década de 2000. Contudo, pelo tempo de contrato de trabalho denota-se rotatividade. 
TABELA 8 -Mapeamento das academias pesquisadas: tipo de contrato de trabalho; \% de EFs por sexo; tempo médio de contrato de trabalho.

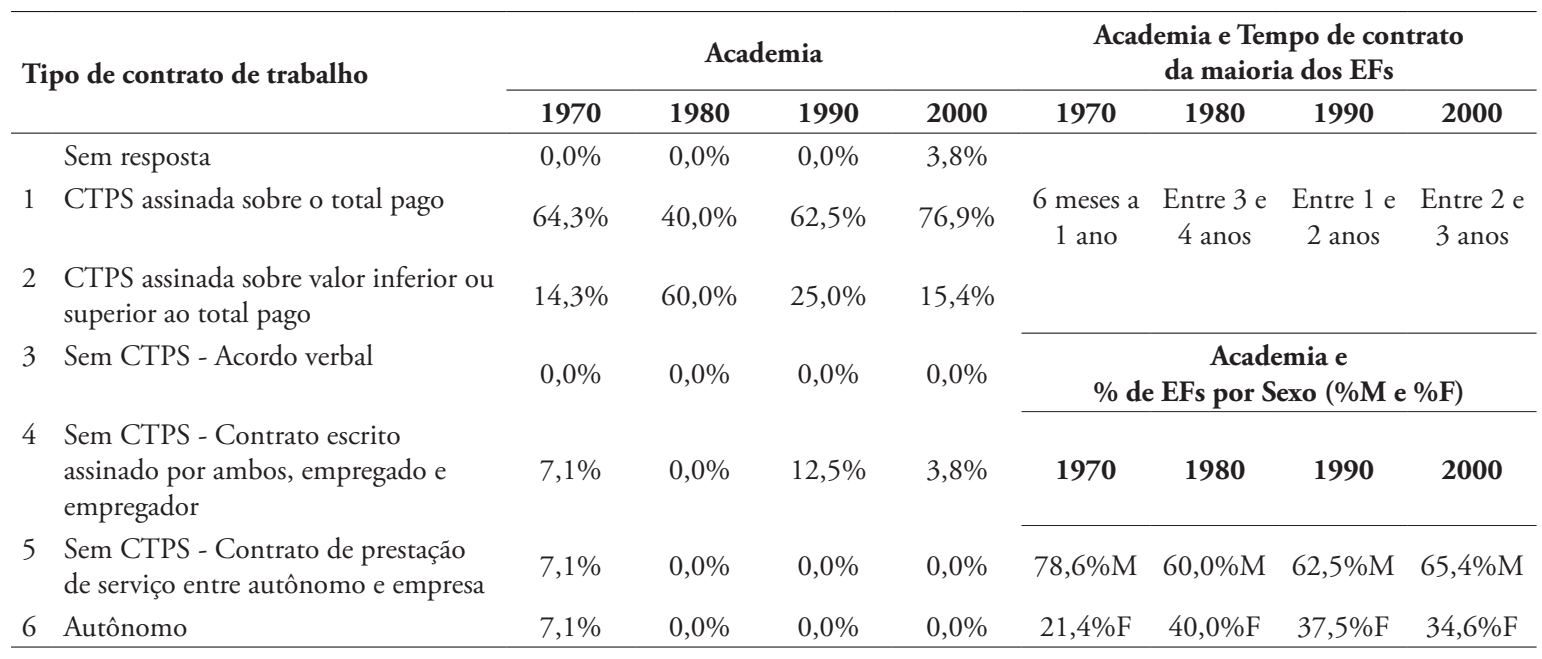

TABELA 9 - Remuneração do EF.

\begin{tabular}{|c|c|c|c|c|c|c|}
\hline \multirow{3}{*}{ Aspectos da remuneração do $\mathrm{EF}$} & \multirow{2}{*}{\multicolumn{2}{|c|}{ Total }} & \multicolumn{4}{|c|}{ Sexo } \\
\hline & & & \multicolumn{2}{|l|}{ M } & \multicolumn{2}{|l|}{$\mathbf{F}$} \\
\hline & n & $\%$ & $\mathbf{n}$ & $\%$ & n & $\%$ \\
\hline \multicolumn{7}{|l|}{ Como é a remuneraçáo do EF? } \\
\hline Sem resposta & 5 & 9,4 & 3 & 5,7 & 2 & 9,4 \\
\hline Hora-aula & 48 & 90,6 & 33 & 62,3 & 15 & 90,6 \\
\hline Outra & 0 & 0,0 & 0 & 0,0 & 0 & 0,0 \\
\hline \multicolumn{7}{|l|}{ Valor da hora-aula é diferente conforme a modalidade? } \\
\hline Sem resposta & 11 & 20,8 & 9 & 17,0 & 2 & 3,8 \\
\hline Sim & 29 & 54,7 & 20 & 37,7 & 9 & 17,0 \\
\hline Ginástica & 20 & $\pm 4,2$ & & & & \\
\hline Nataçáo & 12 & $\pm 4,7$ & & & & \\
\hline Musculação & 10 & $\pm 3,2$ & & & & \\
\hline "Personal trainer" & 110 & \pm 213 & & & & \\
\hline \multicolumn{7}{|l|}{ Salário do EF conforme emprego em R\$ (Média e Desvio-padráo) } \\
\hline Emprego 1 & 700 & $\pm 563,9$ & & & & \\
\hline Emprego 2 & 1.600 & $\pm 1.537,9$ & & & & \\
\hline Emprego 3 & 900 & $\pm 1.046,5$ & & & & \\
\hline Emprego 4 & 700 & $\pm 141,4$ & & & & \\
\hline
\end{tabular}

O Salário Médio referente ao Emprego 2 se mostrou elevado em relação aos demais, neste sentido, é importante lembrar, que para maioria dos EFs a atuação como personal trainer ocupa invariavelmente o segundo lugar, sendo em geral, sua ocupação em seu Emprego 2.
Apesar dos aspectos relacionados ao seu trabalho, o EF avalia que possui uma boa qualidade de vida e um bom investimento em autocuidado com a saúde, sendo ativo fisicamente (ver TABELA 10). 
TABELA 10 - Opinião do EF.

\begin{tabular}{|c|c|c|c|c|c|c|}
\hline \multirow{3}{*}{ Como EF se avalia } & & & \multicolumn{4}{|c|}{ Sexo } \\
\hline & \multicolumn{2}{|c|}{ Total } & \multicolumn{2}{|c|}{$\mathbf{M}$} & \multicolumn{2}{|c|}{$\mathbf{F}$} \\
\hline & $\mathbf{n}$ & $\%$ & $\mathbf{n}$ & $\%$ & $\mathbf{n}$ & $\%$ \\
\hline \multicolumn{7}{|c|}{ Considerando sua carga total de trabalho como julga sua qualidade de vida } \\
\hline Excelente & 3 & 5,7 & 2 & 3,8 & 1 & 5,7 \\
\hline Muito boa & 19 & 35,8 & 15 & 28,3 & 4 & 35,8 \\
\hline Boa & 21 & 39,6 & 13 & 24,5 & 8 & 39,6 \\
\hline Razoável & 10 & 18,9 & 6 & 11,3 & 4 & 18,9 \\
\hline Ruim & 0 & 0,0 & 0 & 0,0 & 0 & 0,0 \\
\hline \multicolumn{7}{|c|}{ Quanto a seu investimento em autocuidado com a saúde } \\
\hline Sem resposta & 1 & 1,9 & 0 & 0,0 & 1 & 1,9 \\
\hline Ruim & 2 & 3,8 & 2 & 3,8 & 0 & 0,0 \\
\hline Razoável & 5 & 9,4 & 3 & 5,7 & 2 & 3,8 \\
\hline Bom & 17 & 32,1 & 11 & 20,8 & 6 & 11,3 \\
\hline Muito bom & 17 & 32,1 & 14 & 26,4 & 3 & 5,7 \\
\hline Excelente & 11 & 20,8 & 6 & 11,3 & 5 & 9,4 \\
\hline \multicolumn{7}{|c|}{ Pratica atividade física } \\
\hline Sim & 48 & 90,6 & 33 & 62,3 & 15 & 28,3 \\
\hline Às vezes & 4 & 7,5 & 2 & 3,8 & 2 & 3,8 \\
\hline Não & 1 & 1,9 & 1 & 1,9 & 0 & 0,0 \\
\hline
\end{tabular}

Os dados da pesquisa evidenciam que o EF demonstra gostar de sua profissão (TABELA 1), mas se sente desvalorizado e insatisfeito ao mesmo tempo com o reconhecimento dado a si (TABELA 12), e quanto a valoração de sua profissão (vide TABELA 11 e 12), tanto que 18,9\% pretendem abandonar a profissão (TABELA 13). Em relação às suas pretensóes profissionais, foi admirável encontrar respostas dos EFs que demonstraram que não se preocupam com este aspecto (22,6\%), este índice revela ou uma baixa conscientização, mobilização e criticidade dos Educadores Físicos perante esta realidade, ou uma indiferença, ligada ao fato de haver muitos EFs em início de carreira como já verificado. Tal questão é aprofundada adiante, após as tabelas.

TABELA 11 - Opinião do EF.

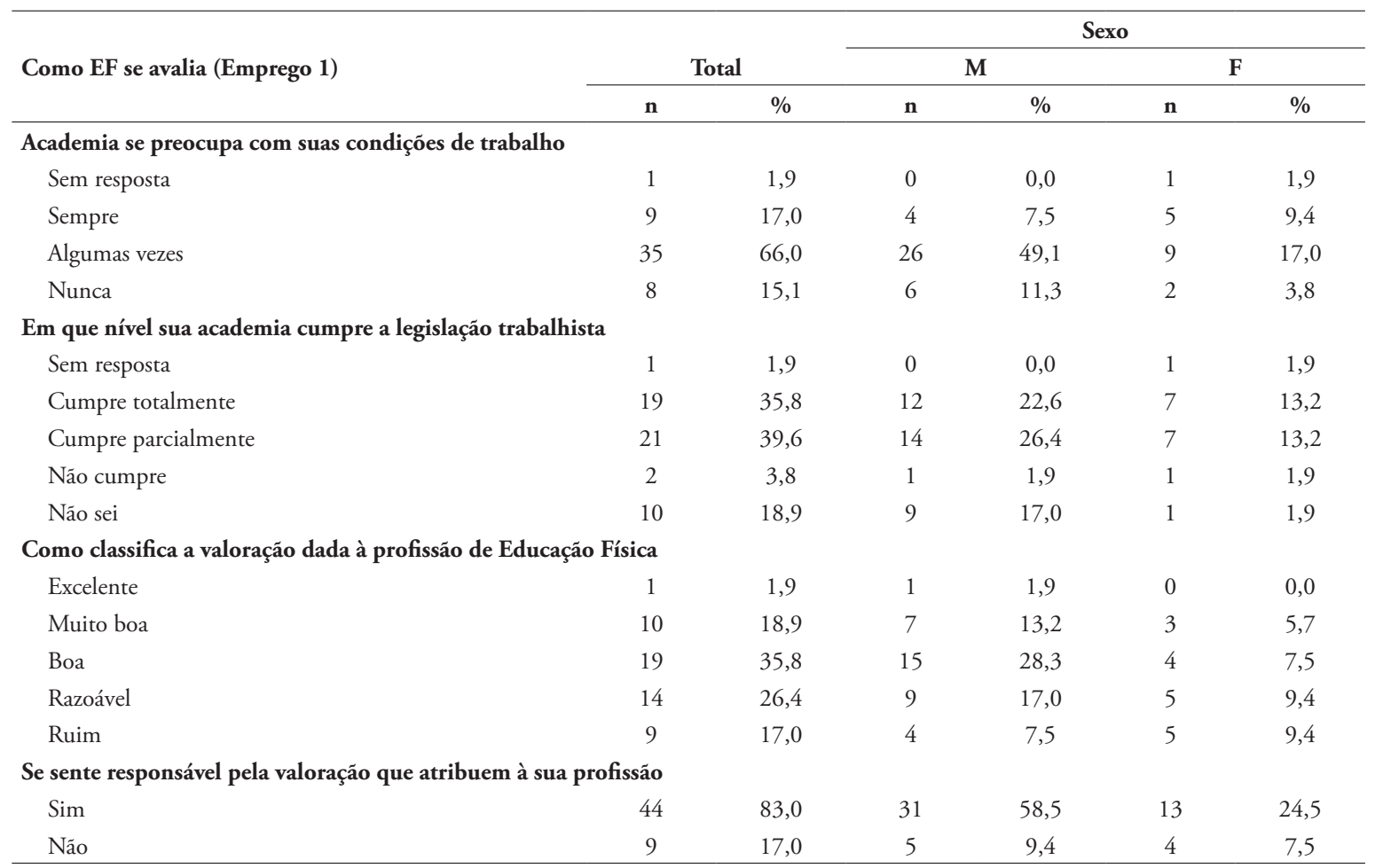


Mendes AD \& Azevêdo PH.

TABELA 12 - Nível de satisfação do EF.

\begin{tabular}{|c|c|c|c|c|c|c|}
\hline \multirow{3}{*}{ Nível de satisfaçáo do EF (Emprego 1) } & & & \multicolumn{4}{|c|}{ Sexo } \\
\hline & \multicolumn{2}{|c|}{ Total } & \multicolumn{2}{|c|}{$\mathbf{M}$} & \multicolumn{2}{|c|}{$\mathbf{F}$} \\
\hline & n & $\%$ & $\mathbf{n}$ & $\%$ & $\mathbf{n}$ & $\%$ \\
\hline \multicolumn{7}{|l|}{ Renda } \\
\hline Péssimo & 5 & 9,4 & 2 & 3,8 & 3 & 5,7 \\
\hline Insuficiente & 11 & 20,8 & 8 & 15,1 & 3 & 5,7 \\
\hline Regular & 26 & 49,1 & 18 & 34,0 & 8 & 15,1 \\
\hline Bom & 9 & 17,0 & 6 & 11,3 & 3 & 5,7 \\
\hline Ótimo & 2 & 3,8 & 2 & 3,8 & 0 & 0,0 \\
\hline \multicolumn{7}{|l|}{ Condiçóes de trabalho } \\
\hline Sem resposta & 2 & 3,8 & 1 & 1,9 & 1 & 1,9 \\
\hline Péssimo & 0 & 0,0 & 0 & 0,0 & 0 & 0,0 \\
\hline Insuficiente & 1 & 1,9 & 0 & 0,0 & 1 & 1,9 \\
\hline Regular & 8 & 15,1 & 7 & 13,2 & 1 & 1,9 \\
\hline Bom & 26 & 49,1 & 18 & 34,0 & 8 & 15,1 \\
\hline Ótimo & 16 & 30,2 & 10 & 18,9 & 6 & 11,3 \\
\hline \multicolumn{7}{|c|}{ Imagem profissional (reconhecimento social - valoraçáo que lhe atribuem) } \\
\hline Sem resposta & 1 & 1,9 & 1 & 1,9 & 0 & 0,0 \\
\hline Péssimo & 0 & 0,0 & 0 & 0,0 & 0 & 0,0 \\
\hline Insuficiente & 1 & 1,9 & 1 & 1,9 & 0 & 0,0 \\
\hline Regular & 11 & 20,8 & 7 & 13,2 & 4 & 7,5 \\
\hline Bom & 25 & 47,2 & 18 & 34,0 & 7 & 13,2 \\
\hline Ótimo & 15 & 28,3 & 9 & 17,0 & 6 & 11,3 \\
\hline \multicolumn{7}{|l|}{ Motivação pessoal do EF } \\
\hline Péssimo & 3 & 5,7 & 1 & 1,9 & 2 & 3,8 \\
\hline Insuficiente & 2 & 3,8 & 2 & 3,8 & 0 & 0,0 \\
\hline Regular & 10 & 18,9 & 4 & 7,5 & 6 & 11,3 \\
\hline Bom & 20 & 37,7 & 16 & 30,2 & 4 & 7,5 \\
\hline Ótimo & 18 & 34,0 & 13 & 24,5 & 5 & 9,4 \\
\hline \multicolumn{7}{|l|}{ Entrosamento com equipe } \\
\hline Péssimo & 0 & 0,0 & 0 & 0,0 & 0 & 0,0 \\
\hline Insuficiente & 1 & 1,9 & 0 & 0,0 & 1 & 1,9 \\
\hline Regular & 2 & 3,8 & 1 & 1,9 & 1 & 1,9 \\
\hline Bom & 24 & 45,3 & 16 & 30,2 & 8 & 15,1 \\
\hline Ótimo & 26 & 19,1 & 19 & 35,8 & 7 & 13,2 \\
\hline \multicolumn{7}{|l|}{ Reconhecimento da direçáo } \\
\hline Péssimo & 4 & 7,5 & 4 & 7,5 & 0 & 0,0 \\
\hline Insuficiente & 8 & 15,1 & 5 & 9,4 & 3 & 5,7 \\
\hline Regular & 14 & 26,4 & 9 & 17,0 & 5 & 9,4 \\
\hline Bom & 17 & 32,1 & 11 & 20,8 & 6 & 11,3 \\
\hline Ótimo & 10 & 18,9 & 7 & 13,2 & 3 & 5,7 \\
\hline \multicolumn{7}{|l|}{ Reconhecimento dos alunos } \\
\hline Péssimo & 0 & 0,0 & 0 & 0,0 & 0 & 0,0 \\
\hline Insuficiente & 0 & 0,0 & 0 & 0,0 & 0 & 0,0 \\
\hline Regular & 4 & 7,5 & 3 & 5,7 & 1 & 7,5 \\
\hline Bom & 25 & 47,2 & 17 & 32,1 & 8 & 47,2 \\
\hline Ótimo & 24 & 45,3 & 16 & 30,2 & 8 & 45,3 \\
\hline
\end{tabular}

610 • Rev Bras Educ Fís Esporte, (São Paulo) 2014 Out-Dez; 28(4):599-615 
TABELA 13 - Pretensões profissionais do EF.

\begin{tabular}{|c|c|c|c|c|c|c|}
\hline \multirow{3}{*}{ Pretensóes profissionais do EF } & & & \multicolumn{4}{|c|}{ Sexo } \\
\hline & \multicolumn{2}{|c|}{ Total } & \multicolumn{2}{|c|}{$\mathbf{M}$} & \multicolumn{2}{|c|}{$\mathbf{F}$} \\
\hline & $\mathbf{n}$ & $\%$ & n & $\%$ & $\mathbf{n}$ & $\%$ \\
\hline Mudar de profissão & 10 & 18,9 & 5 & 9,4 & 5 & 9,4 \\
\hline Fazer pós-graduação & 13 & 24,5 & 10 & 18,9 & 3 & 5,7 \\
\hline Outra & 15 & 28,3 & 10 & 18,9 & 5 & 9,4 \\
\hline
\end{tabular}

As pesquisas sobre as condiçóes de trabalho do Educador Físico possuem um fator que mascara os resultados de algumas pesquisas, a realização pessoal advinda da escolha da profissáo ${ }^{16,29}$. Os resultados de Nogueira ${ }^{7}$, única pesquisa semelhante a está em análise e magnitude, quando visto sob seu aspecto macro, mostram que o Educador Físico possui boas condiçóes de trabalho e está satisfeito com elas, entretanto, quando se analisa cada categoria investigada o resultado náo corresponde ao resultado macro encontrado. Exatamente como encontramos (ver TABELAS 11,12 e 13). Tais constataçóes nos colocam diante de um interessante caso de investigação no campo da saúde do trabalhador, pois, de um lado, pode-se encontrar um profissional que experimenta o prazer na realização de suas atividades laborativas, que tem satisfação no que faz, e, por outro, é possível encontrar uma série de queixas relacionadas à saúde ${ }^{16-19,21,25}$ e aspectos de realização e satisfação profissional ${ }^{16-20,25}$, mesmo em estudantes de Educação Física ${ }^{23}$.

$\mathrm{O}$ que se vê em realidade são Educadores Físicos "em vulnerabilidade"16, à mercê de condições de trabalho que os colocam no cerne de uma contradição materializada na pessoa do próprio Educador Físico, instaurando um paradoxo em que ao cuidar da "saúde e qualidade de vida" de outrem submete a sua "saúde e qualidade de vida” a condiçôes insalubres constituídas por condicionantes de seu trabalho precarizado. Faltam informação e integração da categoria profissional para que se mobilizem quanto a sua formação e colocação no mercado de trabalho, não só no atinente a atender às demandas de mercado, mas também para que tenham condiçóes de propor uma troca justa pela sua mão-de-obra. Que lutem por uma regulação e por uma regulamentação devida do trabalho do Educador Físico.

Os EFs agem como se estivessem à parte de toda situação no mercado de trabalho, quando não estão, como evidencia Alves e TAVAres ${ }^{30}$ :

[...], o trabalhador está subordinado às determinações do capital, mesmo que disso não tenha consciência. [...] O mercado é o ponto para o qual todos convergem e no qual todas as pseudoautonomias se dissolvem. Por mais independente que o indivíduo imagine ser, o produto do seu trabalho terá, em algum momento, de se confrontar com outros, no mercado, onde cada troca imprime a presença da mais-valia, expressando, portanto, a oposição do capital à capacidade viva de trabalho (p.441).

É necessária mudança quanto à postura dos EFs. Notamos nos EFs uma atitude que HobsBawM ${ }^{31}$ caracteriza como "presentificação", onde os jovens "crescem numa espécie de presente contínuo, sem qualquer relação orgânica com o passado público da época em que vivem" (p.13), e a partir desta perspectiva não têm consciência suficiente do passado que os possibilite construir o futuro, já que é nítido o fato de que o EF atuante em academias - um ramo em extenso crescimento e aporte econômico - tem prazo de validade no mercado de academias, e parece não pensar em fazer algo para mudar esta realidade. Ao invés de assumir posição de refém de leis associadas à economia e aos seus imperativos de crescimento ${ }^{31}$, que defendem as formas de exploração falaciosamente como oportunidades de crescimento econômico e de uma nova sociabilidade ${ }^{30}$, o EF tem de se posicionar como sujeito de sua realidade.

Embora seja constantemente referenciado como importante agente promotor de saúde e qualidade de vida, o Educador Físico em função de sua atuação profissional e condiçóes de trabalho em academias de atividades físicas tem sua saúde prejudicada. O que se caracteriza como uma contradição no cerne de sua profissão, visto que é um profissional da área de saúde que degrada sua saúde, por meio de suas condiçóes de trabalho e atuação profissional, ao zelar pela saúde de outrem.

As pesquisas evidenciam aspectos indicadores de precarização, flexibilização e intensificação do trabalho ${ }^{28,30,32-38}$.

$\mathrm{Na}$ revisão bibliográfica, identificamos pesquisas que relacionam o adoecimento e a atuação profissional do EF em academias ${ }^{16-19,21,25}$, trazendo a necessidade de uma maior conscientizaçáo dos profissionais acerca 
dos aspectos patológicos associados ao seu trabalho em academias, com a finalidade de contribuir para a promoção da saúde e prevenção do adoecimento dos EFs, além de ressaltar "a responsabilidade dos empregadores pela adoção de medidas de proteção à saúde dos trabalhadores" 23 .

No atinente a relação de trabalho estabelecida entre Educadores Físicos e academias, ela precisa ser rediscutida e re-significada, para tanto é preciso união dos profissionais para constituição de um sindicato que resguarde a valoração de sua profissão e lhes proteja e das insalubres condiçôes de trabalho, de modo que possam se libertar do ciclo vicioso, tal como tratado por Palma et $\mathrm{al}^{2}{ }^{25}$ - "o professor parece estar preso à uma situação que a própria cultura do 'fitness' criou e deixou se solidificar" (p.350) - o qual traça exigências sobre-humanas sobre o profissional.

A quantidade de estudos leva a crer que as pesquisas sobre mercado de trabalho em Educação Física não têm dado foco específico aos locais de atuação profissional em expansão e às questóes que emergem destes, urgindo, portanto, a necessidade de se formular tais questôes de forma científica ${ }^{33}$. Infelizmente esta realidade não é prerrogativa do EF, é uma reverberação de mudanças no mundo do trabalho ${ }^{34}$, na qual uma boa qualificação profissional não é garantia de um trabalho decente, haja vista as alteraçóes na legislação trabalhista permitidas pelo poder público brasileiro.

\section{Notas}

a. A denominação "Educador Físico", embora não seja apropriada, haja vista, a carga semântica que restringe o que realmente é a área de atuação em Educação Física, é utilizada aqui apenas com a finalidade de abarcar os sujeitos atuantes nos locais que compóem o mercado de trabalho da área de Educação Física. A problematização do termo e sua definição são detalhadas no tópico "Definição de Termos Utilizados" e no Capítulo 3 da dissertação de Mendes 39 .

b. Na revisão bibliográfica feita previamente para este estudo, encontramos 11 estudos sobre o trabalho do EF em academias de atividades físicas. Dos quais: seis ${ }^{16-19,21,23,25}$ abordam, especificamente, a relação entre o trabalho do EF e as reverberaçóes deste em sua saúde, e apenas um aborda as condiçóes de trabalho do EF em academias de atividades físicas ${ }^{7}$.

c. Para mais informaçóes do desenho de pesquisa ver Mendes ${ }^{39}$.

d. Este estudo é parte da Dissertaçáo de Mestrado "Atuação profissional e condiçóes de trabalho do educador físico em academias de atividades físicas" ${ }^{39}$ defendida em 2010 no Programa de Pós Graduação em Educação Física da Faculdade de Educação Física da UnB, tendo a autora sido premiada com Diploma de Honra pela Fédération Internationale D’Education Physique (FIEP) em 2011 e pelo IV Prêmio de Literatura Científica do Colégio Brasileiro de Ciências de Esporte (CBCE) em 2013.

e. São eles: Nogueira ${ }^{7}$; Palma ${ }^{16}$; Palma e Assis ${ }^{17}$; Palma et al. ${ }^{18-19,23,25}$; Milano et al. ${ }^{21}$.

f. Este estudo é parte da dissertação de $\mathrm{MendeS}^{39}$, no qual o questionário utilizado pode ser visto na íntegra.

g. Como em Palma et al. ${ }^{18,23}$.

h. Para mais informaçôes ver Sandmark A, Wiktorin C, Hogstedt C, et al. Physical work load in physical education teachers. Appl Ergon. 1999;30:435-42 e SANDMARK A. Musculoskeletal dysfunction in physical education teachers. Occup Environ Med. 2000;10:673-77, citados por Palma et al. ${ }^{19}$.

i. Estabelecido na CLT artigo no 320, cabível aos professores e não aos instrutores. Diferenciação esta que é feita no SESC por exemplo, entre Educadores Físicos que atuam nas escolas SESC e nos clubes SESC.

j. Na obra de Nogueira ${ }^{7}$, este termo refere-se mais à condiçôes de infraestrutura do local de trabalho.

k. Sistema de aulas padronizadas com utilização de música e coreografia específicas, divulgadas pela empresa Les Mills.

1. Ver Lacerda et al., 2001; Mirbod et al., 1994; Deus e Duarte, 1997 citados por Palma et al. ${ }^{25}$.

m. A pesquisa empírica aqui relatada foi parte de um amplo estudo, fruto da dissertaçáo de mestrado de Mendes ${ }^{39}$.

n. Valoração é o ato ou efeito de valorar, de determinar a qualidade ou o valor de algo; é o juízo crítico avaliativo expresso por alguém sobre algo. 


\section{Abstract}

Work and health of the physical educator in gym: a contradiction at the heart of the profession

Sport and physical activity in Brazil are expanding in number of participants and diversification of activities. This expansion includes the branch of fitness facility, in which Brazil is fourth in the world market. Although the Physical Educator (PE) could be benefited by this expansion, this does not occur. And even being highlighted as a promoter of health and quality of life, there are little research on how the health and quality of life of PE are affected by their professional acting and working conditions. The objective of this research was to bring for scientific evidence some aspects of professional acting and working conditions of PE that work in fitness facility of Brasilia (DF), being used descriptive research with semi-open questionnaire $(n=53)$. It was found that the rapid growth of fitness facility, including these places as the preferred locus to work of newly formed, does not correspond to better working conditions for PEs, due the presence of informality, precariousness, intensification and flexibilization of work, leading PE to work at various jobs [PEs have an average of two jobs (54.7\%), and others PEs have 4 jobs (9.4\%)], causing wear to your health, a contradiction to the essence of the profession. We denote the working conditions are not always favorable, but masked by the personal fulfillment of the vocational choice of profession. Low awareness, mobilization and criticality of PEs face this reality was verified, although some have indicated a desire to abandon the profession. The establishing a new contractuality is required.

KeY woRds: Physical education; Professional acting; Working conditions; Labor market; Quality of the working life; Fitness facility.

\section{Referências}

1. Alves JAB. Cenário de tendências gerais dos esportes e atividades físicas no Brasil. In: DaCosta LP, editor. Atlas do esporte no Brasil [Internet]. Rio de Janeiro: CONFEF; 2006. p.35-6. [citado 21 ago 2013]. Disponível em: http:// www.atlasesportebrasil.org.br/textos/173.pdf.

2. Boschi RF. Cenário de tendências de emprego na área de esportes e atividades físicas. In: DaCosta LP, editor. Atlas do esporte no Brasil [Internet]. Rio de Janeiro: CONFEF; 2006. p.21-37. [citado 21 ago 2013]. Disponível em: http:// www.atlasesportebrasil.org.br/textos/166.pdf.

3. Capinussú JM. Academias de ginástica e condicionamento físico: origens. DaCosta LP, editor. Atlas do esporte no Brasil [Internet]. Rio de Janeiro: CONFEF; 2006. p.6.1-6.2. [citado 23 ago 2013]. Disponível em: http://www.atlasesportebrasil.org.br/textos/145.pdf.

4. DaCosta LP. Cenário de tendências gerais dos esportes e atividades físicas no Brasil. DaCosta LP, editor. Atlas do esporte no Brasil [Internet]. Rio de Janeiro: CONFEF; 2006. p.21.3-21.16. [citado 23 mar 2014]. Disponível em: http://cev. org.br/arquivo/biblioteca/4013539.pdf.

5. Nascimento JV. Realidade e perspectivas do mercado de trabalho em educaçáo física para o Século XXI. Cad Educ Fis MC Rondon. 2000;2:117-36.

6. Bertevello G. Academias de ginástica e condicionamento físico-desenvolvimento. In: DaCosta LP, editor. Atlas do esporte no Brasil [Internet]. Rio de Janeiro: CONFEF; 2006. p.6.3-6.4. [citado 21 ago 2013]. Disponível em: http:// scholar.google.com/scholar?hl=en\&btnG=Search\&q=intitle:Academias+de+ginastica+e+condicionamento+fisico+?+ Desenvolvimento\#1.

7. Nogueira LNSF. Qualidade de vida no trabalho do professor de educação [tese]. Rio de Janeiro(RJ): Universidade Gama Filho; 2006.

8. Mendes AM, Morrone CF. Vivências do prazer-sofrimento e saúde psíquica no trabalho: trajetória conceitual e empírica. In: Medes AM, Borges LO, Ferreira MC, editores. Trabalho em transição, saúde em risco. Brasília: UnB; 2002. p.25-42.

9. Dejours C. A banalizaçáo da injustiça social. 7a ed. Monardim LA, tradutor. Rio de Janeiro: FGV; 2008. 
10. CEPAL. Comissão Econômica para a América Latina e o Caribe. Programa das Naçóes Unidas para o Desenvolvimento (PNUD) e Organização Internacional do Trabalho (OIT). Emprego, desenvolvimento humano e trabalho decente: a experiência brasileira recente [Internet]. Brasília: CEPAL/PNUD/OIT; 2008. [citado 21 ago 2013]. Disponível em: http://scholar.google.com/scholar?hl=en\&btnG=Search\&q=intitle:Emprego,+Desenvolvimento+Humano+e+Trabal ho+Decente:+A+Experiencia+Brasileira+Recente\#0.

11. Cervo AL, Bervian PA. Metodologia científica. 4a ed. São Paulo: Makron Books; 1996.

12. Thomas JR, Nelson JK. Métodos de pesquisa em atividade física. 3a ed. Petersen R, et al., tradutores. Porto Alegre: Artmed; 2002.

13. Gil AC. Como elaborar projetos de pesquisa. 4a ed. São Paulo: Atlas; 2002.

14. Günther H. Como elaborar um questionário. In: Pasquali L, editor. Instrumentos psicológicos: manual prático de elaboração. Brasília: LabPAM/IBAPP; 1999.

15. Bertevello G. Academias de ginástica e condicionamento físico: sindicatos \& associaçóes. In: DaCosta LP, editor. Atlas do esporte no Brasil [Internet]. Rio de Janeiro: CONFEF; 2006. p.6.5-6.6. [citado 21 ago 2013]. Disponível em: http://www.atlasesportebrasil.org.br/textos/146.pdf.

16. Palma A. Vida de professores de educação física que atuam em academias de ginástica: comportamento de risco ou vulnerabilidade? II Conferência do Imaginário e das Representações Sociais em Educação Física, Esporte e Lazer; 2003; Rio de Janeiro, BR. Rio de Janeiro: Universidade Gama Filho; 2003. p.21-9.

17. Palma A, Assis M. Uso de esteróides anabólico-androgênicos e aceleradores metabólicos entre professores de educação física que atuam em academias de ginástica. Rev Bras Cienc Esporte. 2005;27:75-92. Disponível em: http://rbceonline. org.br/revista/index.php/RBCE/article/view/135.

18. Palma A, Abreu RA, Cunha CA. Comportamentos de risco e vulnerabilidade entre estudantes de educação física. Rev Bras Epidemiol. 2007;10:117-26.

19. Palma A, Azevedo APG, Ribeiro SSM, Santos TF, Nogueira LNSF. Saúde e trabalho dos professores de educaçáo física que atuam com atividades aquáticas. Arq Mov. 2006;2:81-100.

20. Espírito-Santo G, Mourão L. A auto-representação da saúde dos professores de educação física. Rev Bras Cienc Esporte. 2006;27:39-55.

21. Milano FM, Palma A, Assis M. Saúde e trabalho dos professores de educação física que atuam com ciclismo indoor. Lect Educ Fis Deportes. 2007;12. Disponível em: http://www.efdeportes.com/efd109/saude-e-trabalho-dos-professoresde-educacao-fisica-que-atuam-com-ciclismo-indoor.htm.

22. Benedetti TB, Ouriques R. Análise ergonômica do trabalho de professores de ginástica em academias. Lect Educ Fis Deportes. 2007;11. Disponível em: http://www.efdeportes.com/efd106/analise-ergonomica-do-trabalho-de-professoresde-ginastica-em-academias.htm.

23. Palma A, Jardim S, Luiz RR, Silva Filho JF. Trabalho e saúde: o caso dos professores de educação física que atuam em academias de ginástica. Cad IPUB UFRJ. 2007;13:11-30.

24. Krug RR, Damásio W, Conceição VJS, Krug HN. Perfil dos profissionais de educaçáo física que atuam em academias de musculação na regiáo central da cidade de Criciúma-SC. Bol Educ Fis. 2009. Disponível em: www.boletimef.org/ biblioteca/2175/artigo/boletimef.org_perfil-dos-profissionais-de-educacao-fisica-em-academias-de-musculacao.pdf.

25. Palma A, Mattos UAO, Almeida MN, Oliveira GEMC. Nível de ruído no ambiente de trabalho do professor de educação física em aulas de ciclismo indoor. Rev Saude Publica. 2009;43:345-51.

26. Soriano JB, Winterstein PJ. Satisfação no trabalho do professor de Educação Física. Rev Paul Educ Física. 1998;12:145-59.

27. Delgado MA. Ocupação do mercado de trabalho em educação física na cidade de Campinas, devido a formação profissional [dissertação]. Campinas(SP): Universidade Estadual de Campinas; 1999. p.81.

28. Dal Rosso S. Mais trabalho! A intensificação do labor na sociedade contemporânea. São Paulo: Boitempo; 2006.

29. Santos GE, Silvestrini J, Silva VR. Comparação entre o perfil do profissional de academia de musculação e o perfil do profissional da Educação Física escolar. Lect Educ Fis Deportes. 2008;12. Disponível em: http://www.efdeportes.com/ efd116/perfil-do-profissional-da-educacao-fisica.htm.

30. Alves MA, Tavares MA. A dupla face da informalidade do trabalho: "autonomia" ou precarização? In: Antunes R, editor. Riqueza e miséria do trabalho no Brasil. São Paulo: Boitempo; 2006. p.425-44.

31. Hobsbawm E. Era dos extremos: o breve século XX (1914-1991). São Paulo: Companhia das Letras; 1995. v.2.

32. Telles VS. Pobreza e cidadania: precariedade e condiçóes de vida. In: Martins HHTS, Ramalho Junior, editores. Terceirização: diversidade e negociação no mundo do trabalho. São Paulo: Hucitec CEDI/NETS; 1994.

33. Antunes R. Os sentidos do trabalho: ensaio sobre a afirmação e a negação do trabalho. São Paulo: Boitempo; 1999.

614 • Rev Bras Educ Fís Esporte, (São Paulo) 2014 Out-Dez; 28(4):599-615 
34. Galeazzi I. Precarização do trabalho. In: Cattani AD, Holzmann L, editores. Dicionário de trabalho e tecnologia. 2a ed. Porto Alegre: UFRGS; 2006. p.203-7.

35. Verenguer RCG. Mercado de trabalho em educação fisica: significado da intervenção profissional à luz das relaçóes de trabalho e da construção da carreira [dissertação]. Campinas(SP): Universidade Estadual de Campinas; 2003.

36. Holzmann L, Piccinini V. Flexibilização do trabalho. In: Cattani AD, Holzmann L, editores. Dicionário de trabalho e tecnologia. 2a ed. Porto Alegre: UFRGS; 2006. p.131-3.

37. Tosta TLD. Antigas e novas formas de precarizaçáo do trabalho : o avanço da flexibilização entre profissionais de alta escolaridade [dissertação]. Brasília(DF): Universidade de Brasília; 2008.

38. Kallenberg AL. O crescimento do trabalho precário: um desafio global. Rev Bras Ci Soc. 2009 [citado 21 ago 2013];24:21-30. Disponível em: http://www.scielo.br/pdf/rbcsoc/v24n69/02.pdf.

39. Mendes AD. Atuação profissional e condições de trabalho do educador físico em academias de atividades físicas [dissertaçáo]. Brasília(DF): Universidade de Brasilia; 2010.

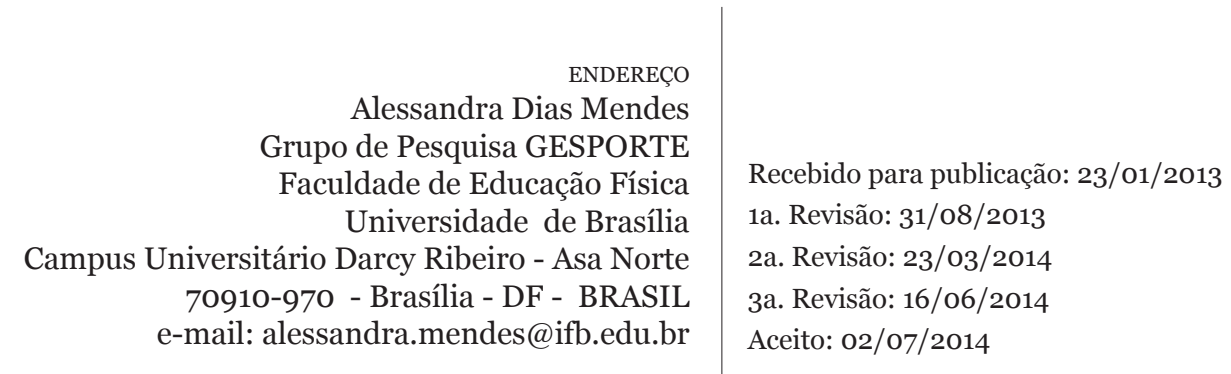

Rev Bras Educ Fís Esporte, (São Paulo) 2014 Out-Dez; 28(4):599-615 • 615 